\title{
Erratum to: Oscillating dark energy model in plane symmetric space-time with time periodic varying deceleration parameter
}

\author{
M. Shen ${ }^{1}$ - L.P. Jiang ${ }^{1}$
}

Received: 26 February 2015 / Accepted: 26 February 2015 / Published online: 28 February 2015

(C) Springer Science+Business Media Dordrecht 2015

Erratum to: Astrophys. Space Sci. (2014) 354: 607-610

DOI 10.1007/s10509-014-2104-7

The name of the first author is wrong and should read:

M. Shen

The online version of the original article can be found under doi:10.1007/s10509-014-2104-7.

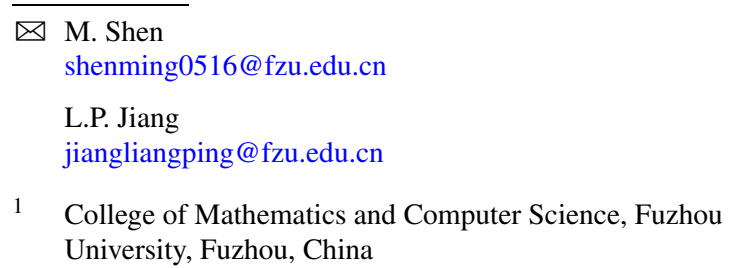

